\title{
Captura de movimento e animação como meio de criação e treinamento em performance.
}

Devising and Movement Training with Performance Capture and Animation

Jeanine Thompson ${ }^{1}$

Vita Berezina-Blackburn ${ }^{2}$

Alex Oliszewski ${ }^{3}$

\section{Resumo}

Em 2014, um grupo de estudantes, professores e funcionários do Departamento de Teatro, Departamento de Design e do Centro de Computação Avançada para Artes e Design (ACCAD) da Ohio StateUniversity (OSU) se uniram para elaborar e criar a peça "Thereis no silence" baseada na vida e obra do importante mímico francês Marcel Marceau. Em 2001, a possibilidade de realizar, pela primeira vez na história, uma performance de Marceau, por meio de captura de movimento feito pelo ACCAD, proporcionou ao grupo a oportunidade artística e tecnológica de integrar animação digital e performance de avatares virtuais em tempo real em seu trabalho. O processo de elaboração revelou semelhanças entre a prática da mímica e a atuação em ambientes virtuais, oferecendo assim, novas possibilidades criação com novas mídias.

\section{Palavras-chave}

Marcel Marceu; mímica; teatro virtual; captura de movimento; avatares.

\begin{abstract}
In 2014 a group of students, faculty and staff at the Ohio State University's (OSU) Department of Theatre, Department of Design and Advanced Computing Center for the Arts and Design (ACCAD) joined their creative energies to devise the play "There is No Silence" based on the life and works of the iconic French mime Marcel Marceau. Marceau's history of being the first performance artist motion captured at ACCAD in 2001 afforded the group artistic and technological opportunities to integrate digital animation and performance of real-time virtual avatars into their work. The process of devising revealed parallels between the practices of mime art and performing with virtual environments and offered new insights for devising with media.
\end{abstract}

\section{Keywords}

Marcel Marceau; mime; virtual theatre; motion capture; virtual avatars.

\footnotetext{
${ }^{1}$ Professor and Movement Theatre Specialist, Department of Theatre, Ohio State University

${ }^{2}$ Animation and Motion Capture Specialist, Advanced Computing Center for the Arts and Design, Ohio State University

${ }^{3}$ Associate Professor of Theatre Media Design, Department of Theatre, Ohio State University
} 


\section{Introduction}

In this writing we would like to discuss the technological, pedagogical and conceptual aspects of setting up the devising media environment and process for student created performance based on the life and works of Marcel Marceau. There Is No Silence is a two-hour mediated performance about the life and work of the great French mime artist. It was collaboratively created through a year and half-long devising process and partnership between the Ohio State University's (OSU)Department of Theatre and the Advanced Computing Center for the Arts and Design (ACCAD) an OSU research center for graduate and postgraduate investigations in $3 \mathrm{D}$ animation and interactive technologies contextualized in many disciplines such as design, theater, dance, computer science, art, architecture, music and musicology, art history, psychology, medicine, veterinary science and more. The play premiered in April in 2014 at OSU's Department of Theatre.

The collaborative process of designing the devising environment and the subsequent devising process took about 15 months. The faculty and staff that shaped this process came from the areas of physical theatre and mime (Jeanine Thompson), 3D animation and motion capture technology (Vita BerezinaBlackburn), media design (Alex Oliszewski), video art (Janet Parrott), playwriting (Jen Schlueter), scenic design (Brad Steinmetz), costume (Natalie Cagle), and lighting (Andy Baker). The devising, script writing, assistant directing and production were carried out by a mix of mostly graduate and a few undergraduate students, over fifty in total, from the Department of Theatre and two graduate students from the Department of Design. The play was devised and performed by the nine members of the MFA acting cohort ${ }^{4}$.

The technologies that shaped the devising process and live performance were integrated throughout the production. They included a projection system that wrangled live performance animation, pre-recorded 3D and 2D animation, prerecorded video sequences and projection lighting for a live silhouette shadow per-

\footnotetext{
${ }^{4}$ Master of Fine Arts in acting. In the case of OSU Theatre Department it is a group of students who enter the program in the same year. They curriculum and experience is set up in a way that they form an ensemble, a cohort.
} 
formance. The six movable projection surfaces included a cyclorama, two rear projection screens and a black scrim that were flown in and out of the performance space as well as two smaller portable screens. The live performance animation was powered by a Vicon optical motion capture system that was set up on the stage to provide real time full body tracking for two actors and a prop. The 3D virtual environments and interactive setups were designed and operated by Vita Berezina-Blackburn, Tom Heban and Sheri Larrimer. Pre-recorded facial motion capture was facilitated via Faceshift software and Kinect sensor. The integration of $3 \mathrm{D}$ environments into the mediated environment that also included live silhouette acting required additional video layering, simultaneous front and rear projection setup and inclusion of other media which was handled through an Isadora based system designed by Alex Oliszewski.

The setup also included a full proscenium sized automated curtain system that was custom designed by Brad Steinmetz and allowed for dynamic framing of live and projected action. The automated curtain was made of three independently operated curtains: two that moved side to side and one that moved up and down. Together they could be programmed to move in any configuration of these three angles across the entire proscenium stage.

\section{Background and Inspiration}

Before we discuss the ways in which the technological elements functioned in devising and production of There is No Silence, we would like to address the reason for selecting and incorporating specific interactive technologies into this work.

Though the research and creative process for this production took a year and half, Jeanine Thompson's interaction with the play's subject, Marcel Marceau, spanned over 20 years. Marceau, as an artist and human being, was of profound influence and inspiration to her.

Marceau was born in France in 1923 and he passed in 2007. As a young man, he was an actor and a painter. During the German occupation of France, Marceau worked with the French Resistance where he saved the lives of numer10 
VIS

Revista do Programa de Pós-graduação em Arte da UnB

ous children by altering their identity cards and entertaining them as he lead them to safety across the French border. Later Marceau introduced the world to the art form of mime. He was best known for his beloved character Bip. For over fifty years he toured the world with his solo performances, performed on television and in many films. Marceau was also a magnificent painter with a style similar to Marc Chagall's.

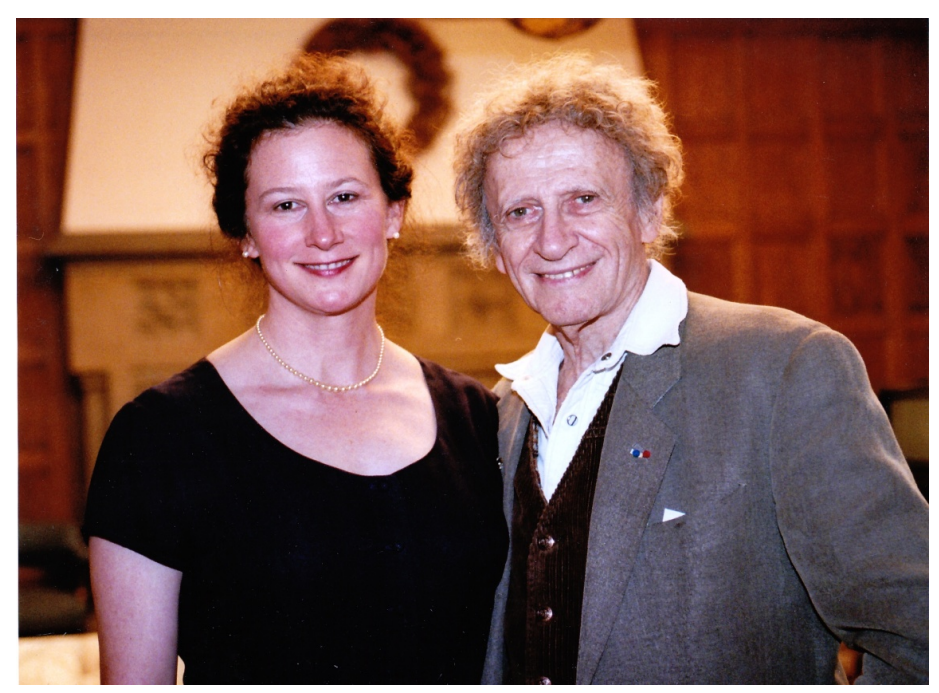

Caption: Marcel Marceau and Jeanine Thompson at during the 2001 workshop at OSU

Jeanine Thompson worked very closely with Marceau - studying with him, demonstrating for his teaching, receiving his coaching for her performances, and producing his workshops in the United States. Four intensive workshops with Marcel Marceau were held at OSU. He gave lectures and performances, and WBNS television filmed and aired a documentary about his time at OSU called The Maestro of Mime. OSU presented him with an Honorary Doctorate degree. In 2001, Theatre and ACCAD joined together to motion capture Marcel Marceau's signature movements ${ }^{5}$.

\footnotetext{
${ }^{5}$ Signature movements can be observed as repeating in an artist's choreography and remembered most vividly by the audience. Some of Marceau's signature movements are "Leaning Against the Bar" or "Walking Against the Wind". You can observe them in this video for instance, starting at 0:45 https://www.youtube.com/watch?v=-PMDYjD21E0

One would prepare to perform another person's signature movements by studying them from as many angles as possible.
} 
VIS

Revista do Programa de Pós-graduação em Arte da UnB

In preparing for capturing Marceau in 2001, Jeanine was captured doing some of his movements. She noticed that the motion of breathing, a primary aspect of Marceau's technique, was not properly captured due to the optical marker placement that prioritized skeletal joints. Upon Jeanine's suggestions additional markers were placed on both sides of the upper part of the chest and the back. This change captured and made more visible the inhalation and exhalation of breath.

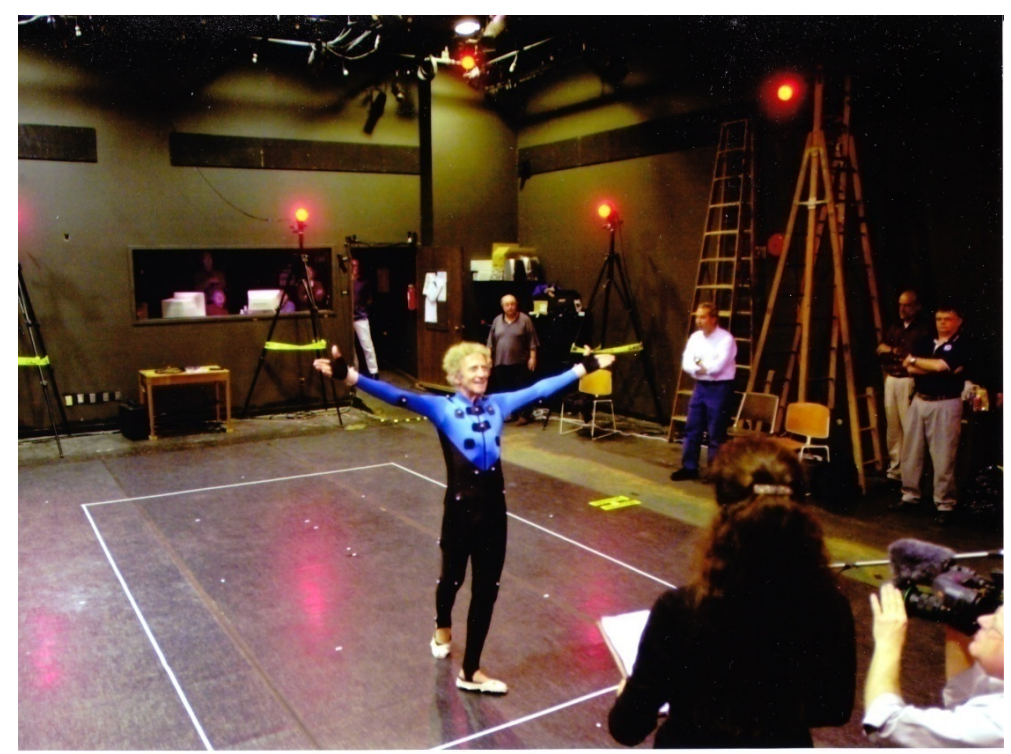

Caption: Marcel Marceau during a 2001 motion capture session at ACCAD

At first Marceau was very hesitant to get into the motion capture suit and to have his skeletal form rendered into a point cloud. But after performing the first take and watching the reconstructed data, he realized that the technology actually did capture the essence of his movement, and he said, according to Jeanine Thompson (personal communication, April 20, 2001), “That's me! Very good! Let's begin." The original capture plan called for only a handful of his signature movements, but after he got going, and what frequently happened with him, he continued to go for much longer and to perform far more material than had been originally planned. He performed his conventions of character, many iconic illusions, including leaning against the bar and walking against the wind, and he finished with a performance of a full-length piece called The Eater of Hearts. 
Since the late 1990s several academic institutions and artistic groups gained access to the optical motion capture technology. Several prominent choreographers such as Trisha Brown, Merce Cunningham, Bill T Jones, and Bebe Miller captured their performances. In some cases the data was captured for specific visualization projects such as Bill T Jones's Ghost Catching done in collaboration with the Open Ended Group and visualizing motioncaptured choreography through virtual avatars and sophisticated projection surface setup. ${ }^{6}$ In other cases it laid foundation for teaching and analyzing choreographic thought like the broadly contextualized Forsythe Company’s Motion Bank project ${ }^{7}$.

Regardless of the specifics of these projects the performance data of several movement artists remain available at least hypothetically for a much wider spectrum of engagement than their original research goal. There are many more potential options for viewing, interacting with and visualizing the data not to mention the motion analysis. As a form of performance documentation, motion (or performance) capture reduces the body to selected points where markers are placed. From the trajectories of these points simplified skeletal form is reconstructed. What becomes highlighted in this type of visualization are the timing and manifestation of weight in joint movement, the clarity of idling states as well as transitions into and out of a performative state, and other nuances that may be obscured by movement qualities and intentions communicated through facial expression, flesh and clothing of a performer when observed live, on film or video. Through the use of computer motion remapping it is possible to transfer the shape and timing of performer's motions onto different figurative and abstract visual forms allowing new ways of visually perceiving human movement.

A choreographer and researcher Kim Vincs (2011:3) who works with motion capture reflects upon ways of seeing movement in the marker data:

The eye, in the sense of its dominating scopic perspective, has no privilege in a motion capture-enabled environment. The eye's habitual ways of conceptualizing bodies are displaced by

${ }^{6} \mathrm{http}: / /$ openendedgroup.com/artworks/gc.html

${ }^{7} \mathrm{http}$ ://www.motionbank.org/ 
motion capture, which is not so much more accurate, as differently accurate, organized via designated points (markers) and trajectories, rather than by lines and surfaces. Marker data, as well as being de-hierarchized, is semantically blind. A raw marker trajectory does not 'know' that it is part of a system. It is simply a record of where a particular point on the surface of the body travelled, and at what speed. No specific marker is more important than any other. The fact that the significance of marker data trajectories is not predicated on their place within a skeletal organization of the body allows me to think differently about what those trajectories could be.

Marceau's hesitation over how accurately the motion capture data represented his movements was not his only concern. The control over potential subsequent use of the data in 3D animated films was another reason for apprehension. His movements could be used to drive characters that sold commercial products, which was unacceptable and influenced his decision to limit the parties and contexts of using the data.

Marceau's performance capture data along with his American Archive acquired from his Mime Foundation formed the Marcel Marceau archive at OSU's Theatre Research Institute (TRI) and had been available for viewing upon request but hardly for any deeper engagement, at least for parties outside the university. Reconnecting with this data in 2013 with an idea of devising a play became a call to action by Jeanine Thompson to make the data visible again, ironically echoing the central quest of the mime art "to make the invisible visible" and contribute to the development of ways to engage with the performance data for artistic, educational and technological reasons. As welooked for ways of engaging with the motion capture material, the two clear directions were identified: the educational use of Marceau's motion capture data in teaching the mime technique andthe development of a mediated devising environment.

The quality of motion capture and tracking technologies today allows film makers to facilitate high fidelity virtual avatar movements in real time. This has been successfully utilized in the phenomenon of virtual production. It was first introduced on the set of James Cameron's $\operatorname{Avatar}^{8}$ and since then has been widely

${ }^{8}$ http://www.cgchannel.com/2012/05/fmx-2012-where-next-for-virtual-production/ 
VIS

Revista do Programa de Pós-graduação em Arte da UnB

used in the filmmaking industry. At the core of virtual production lies the idea of allowing the director and camera person to view physical actors in real-time as virtual characters inside a virtual set through a portable physical monitor with mocap sensors. The operator physically manipulates the portable monitor while the computer translates their motions to the movement of the virtual camera. The virtual set and actors can be scaled to fit the need of a shot: ranging from an intimate close-up to an aerial view. The operator can treat the virtual camera as a handheld camera or a steady cam. This setup enables the director and camera person (in case of James Cameron this was the same person) the freedom to improvise and make spontaneous decisions since they are able to watch actors perform as virtual characters in a virtual environment while simultaneously communicating their instructions rather than having to rely on the animators to redo camera motion or having to re-record the actors' performance days later. The actors can be given instant directions to make adjustments ranging from their location in space to performance qualities of their virtual characters. The camera operator can frame action with a virtual camera: a device combining tracking sensors and a portable monitor (i.e. tablet) that shows the view of a virtual scene. If live camera operation was not satisfactory while the actors were performing, the virtual scene can be replayed and re-shot immediately without live actors' participation, still allowing the operator to act as if filming a live scene.

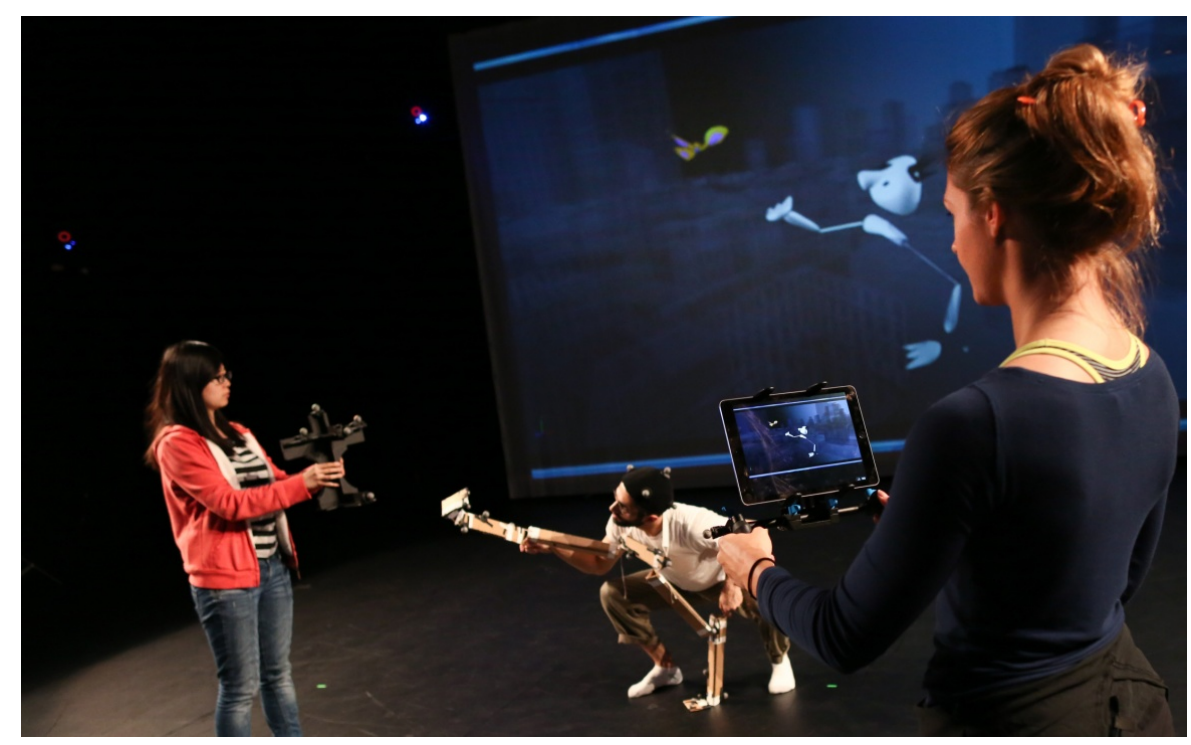

Caption: Students working with virtual camera and real time puppets at ACCAD 
The traditional film format makes characters and environments belong unequivocally in the virtual realm. Bringing the elements of virtual production onto a live stage offers the opportunity for the virtual worlds to form visual continuity with the physical realm via actors that perform through and alongside them. The opportunity for an actor to devise their virtual performance in real-time became a compelling goal for us, just as valuable as the director's ability to work directly in the virtual format.

Having experimented with virtual production for animated films at the ACCAD Motion Lab and being the holders of Marceau's archival performance capture data were the two fortunate factors that converged for the making of There is No Silence and setting up a platform for experimenting with virtual production liveon stage.

\section{Motion/Performance Capture as Part of Mime Training}

Admittedly, using technology in mime training may not be the first thing that comes to mind when dealing with the art form for which a blank slate is a critical starting point. Thinking historically, perhaps it is thebareness, the void, created by the war, destruction and displacement that yielded the metaphor of emptiness for Marceau's stage ofMarceau. It fueled the creation of his character Bip and its appreciation by his early audiences: the groups of children whom Marceau helped escape the Nazis and the American GIs who left the familiar shores to fight in France (Marceau, 2002). By contrast one also has to wonder how material and visual abundance that saturates the Western culture today affects the perception of mime and possibly diminishes the poignancy of visions rendered through gestures. The risk of rendering visible that which is already real can be daunting enough for an artist. Technology, especially the less familiar one, like motion capture, can add yet another level of abstraction and reduction of expressiveness. What can this journey possibly yield?

To prepare the MFA actors to perform and devise with technology we conducted three preliminary week long workshops that focused on utilizing motion capture for learning mime performance, research video projection options and 
VIS

Revista do Programa de Pós-graduação em Arte da UnB

devise mediated scenes that combined live mocap tracking, animation and silhouetted performance.

As Jeanine Thompson began teaching the traditional format sessions of her Mime Class, the students focused on print, film and video materials from the Marceau Archive at the Ohio State University's Theatre Research Institute as well as live coaching. Midway through this class, the media design and animation team held aworkshop on engaging the group with Marceau's motion capture material in ways beyond observation of the recorded movement on a computer screen. The chosen adagio At the Bar was available for viewing in a format that allowed visibility of markers or a simple virtual human form. In the pre-workshop phase the media design group experimented with viewing the data through a head mounted display with attached motion capture sensors allowing the viewer to physically walk around the data in order to view it from different perspectives. While the viewer walked around the physical space, the motion capture system tracked their location and head orientation, and displayed the correct view of the virtual environment in which a recorded motion capture sequence of Marceau's performance was playing back on a loop.

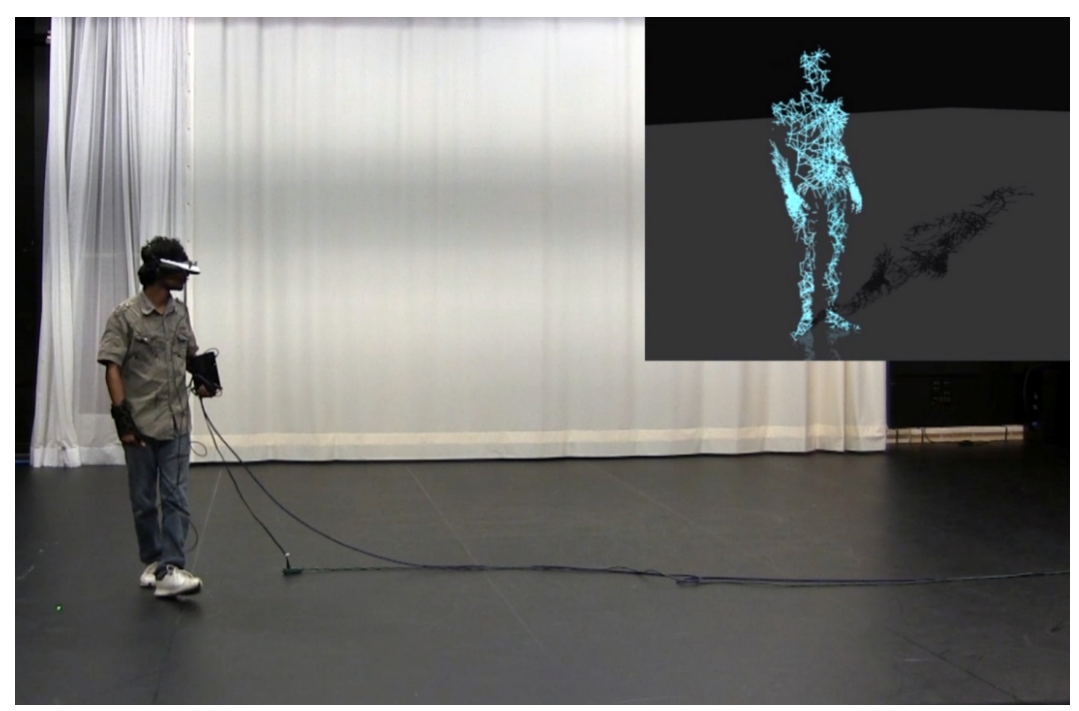

Caption: Viewing the motion capture performance of Marceau through Sony head mounted display that is motion tracked while the viewer is walking around the mocap volume

Even though the full body movement of a person wearing a head mounted display (HMD) could be trackable, the tethered HMD made this arrangement less 
VIS

Revista do Programa de Pós-graduação em Arte da UnB

than ideal for an active physical performance, such as mimicking the adagio or seeing the reaction of the live audience. A single screen feedback, mirroring the actors' performance in the virtual space, was a somewhat limited form of visual feedback since actors always had to turn their heads to check their avatars' appearance. On the other hand, the setup with three projection screens surrounding the motion capture tracking area allowed several mirror-like views of virtual avatars driven by freely moving actors while they were performing. This also permitted up to four actors to be trackable and visible at a time.

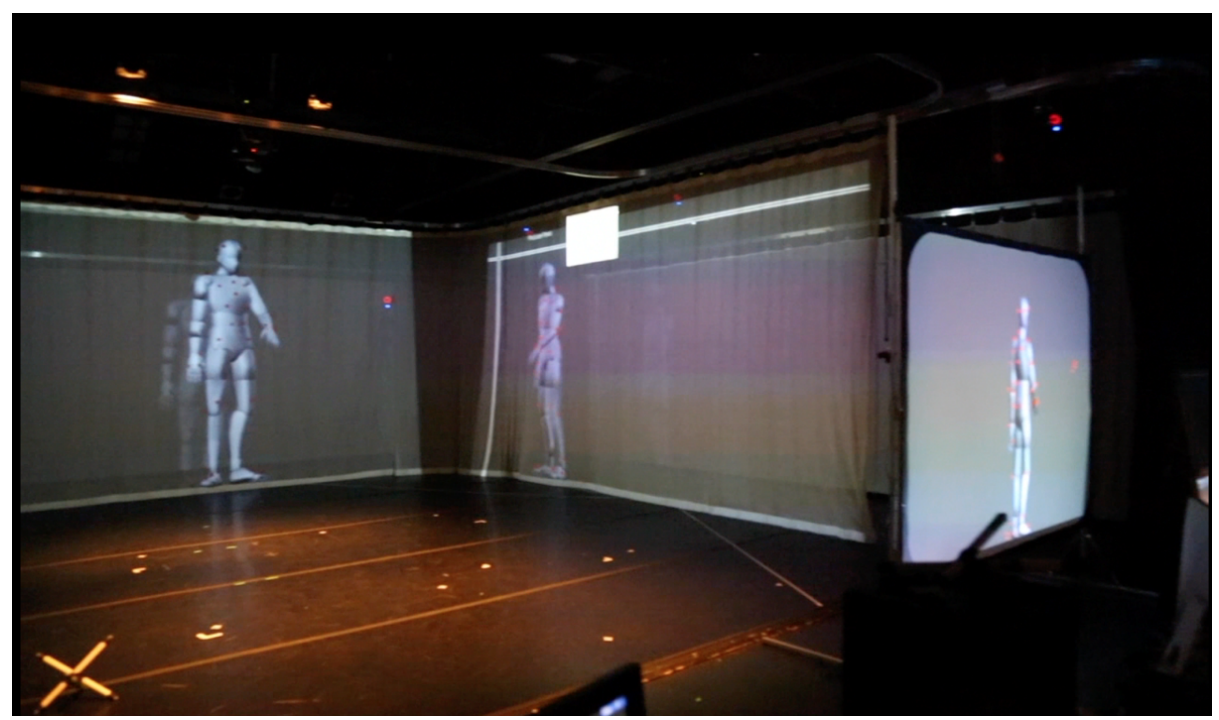

Caption: Projections of Marceau's motion capture performance visualized with a neutral virtual avatar and projected on screens surrounding the mocap volume allowed actors to see the correct angle of this visual reference no matter where they were facing

All projection streams were wrangled in Isadora and took live feeds from Autodesk Motionbuilder that remapped real time performance tracked by the Vicon system onto a virtual avatar. It also played back recorded sequences. The design of thevisual feedback system was tested by student actors. They indicated a preference for a larger projection size of the virtual avatar to a life-sized version for easier visibility. They also requested an ability to adjust the playback speed of the recorded data in order to clarify movement nuances.

Focusing on the use of mocap in mime training each actor was captured performing their version of the At the Bar adagio. For viewing and comparing 
VIS

Revista do Programa de Pós-graduação em Arte da UnB

their performances with the original one of Marceau's, the marker movement was remapped on the same neutral human form avatar.

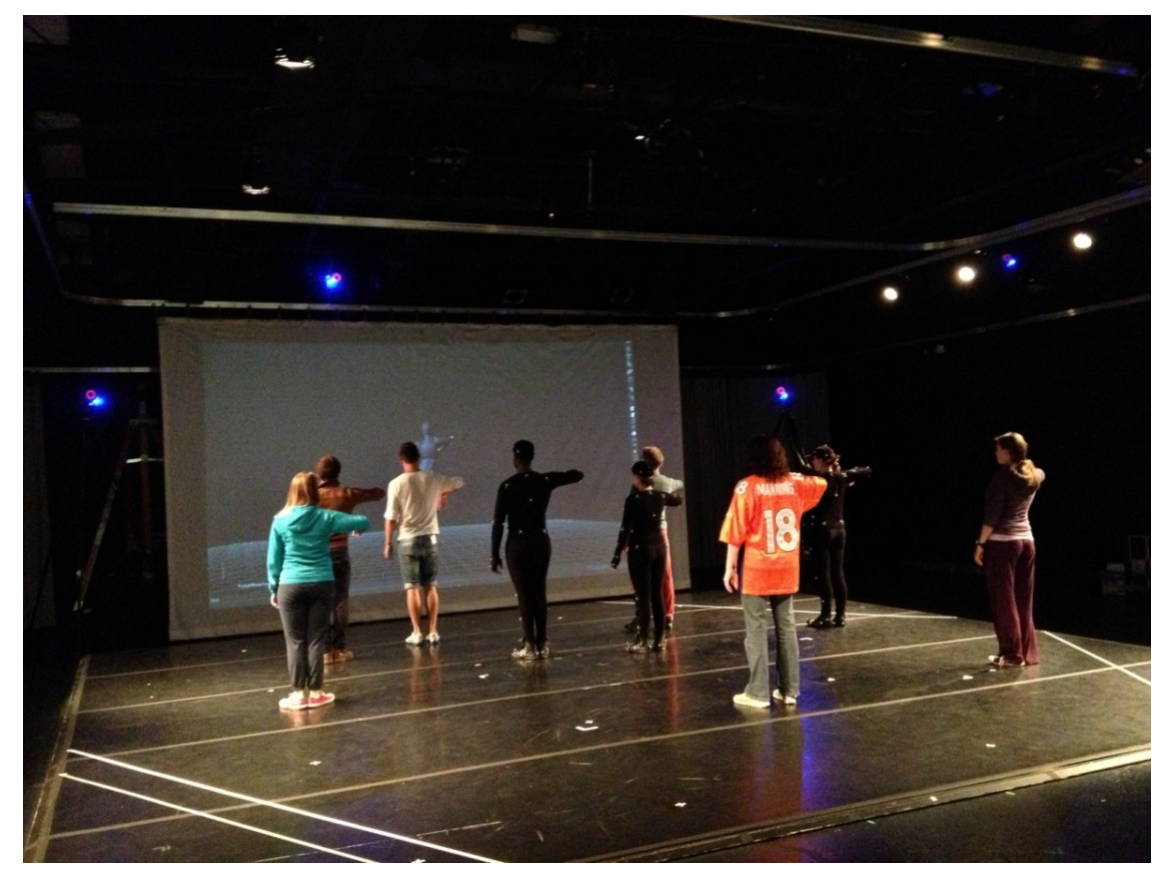

Caption: The MFA actors rehearsing Marceau's adagio At the Bar with projected recording of Marceau's motion captured performance. Three actors are being motion captured during this exercise without seeing real time visual feedback of their avatars.

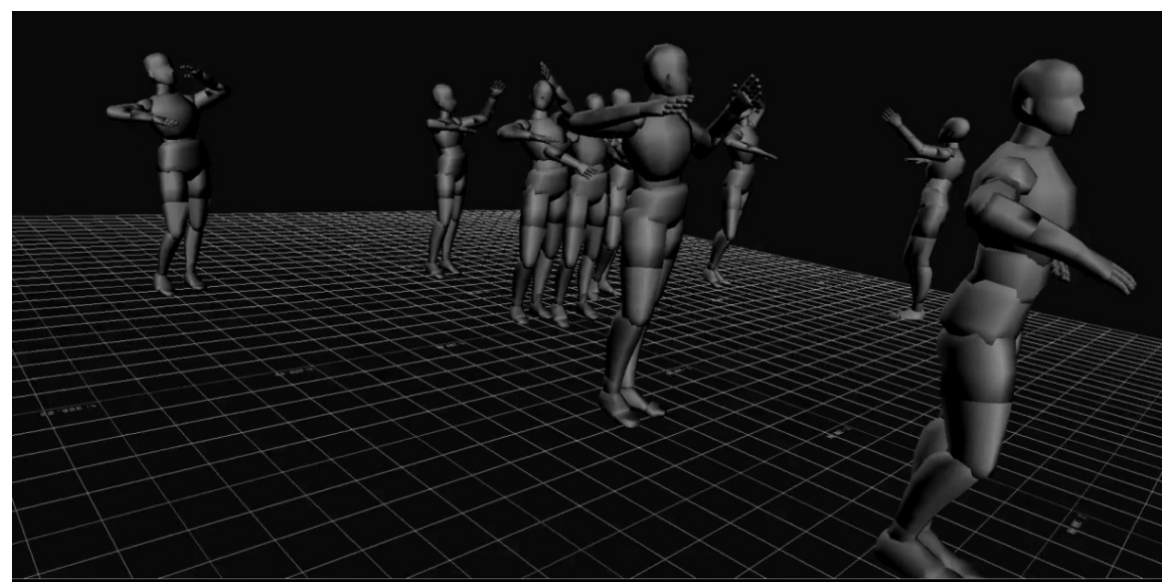

Caption: A view of motion captured versions of adagio, performed by all actors, combined in one 3D virtual scene.

Thus when compared side by side, it was the qualities of movement rather than bodily appearance that constituted the observable differences. Examining side-by-side versions of the same adagio visualized with the same avatar model and thus removed ability to recognize individual performer's appearance, students 
VIS

Revista do Programa de Pós-graduação em Arte da UnB

discovered many surprising nuances of timing and weight qualities that were unique to individual performers. Students reported observing individual qualities in the performances of the same adagio such as tense shoulders, or loose knees, or differences in timing and scale of specific gestures, length and tempo of stride. These qualities became so visible that the students had no trouble guessing the identity of each performer. The actors found this to be very informative and helpful in understanding their own movement styles.

While very few students struggled with memorizing the sequence of actions in the adagio, the gesture shapes ran a whole gamut of variations. The most intriguing observation made by the actors watching each other's captured performances was their ability to recognize a performer's identity based solely on their idiosyncratic timing and weight qualities of the motion. And while almost nobody was able to get the timing identical to Marceau's original performance, a couple of performances were identified as most interesting based on the movement variations deliberately introduced by the actors. This experience inspired a scene in the play There Is No Silence where actor Patrick Wiabel devised an adagio that, while performed live, functioned as a duet when viewed in the same virtual scene with simultaneous playback of Marceau's original performance.

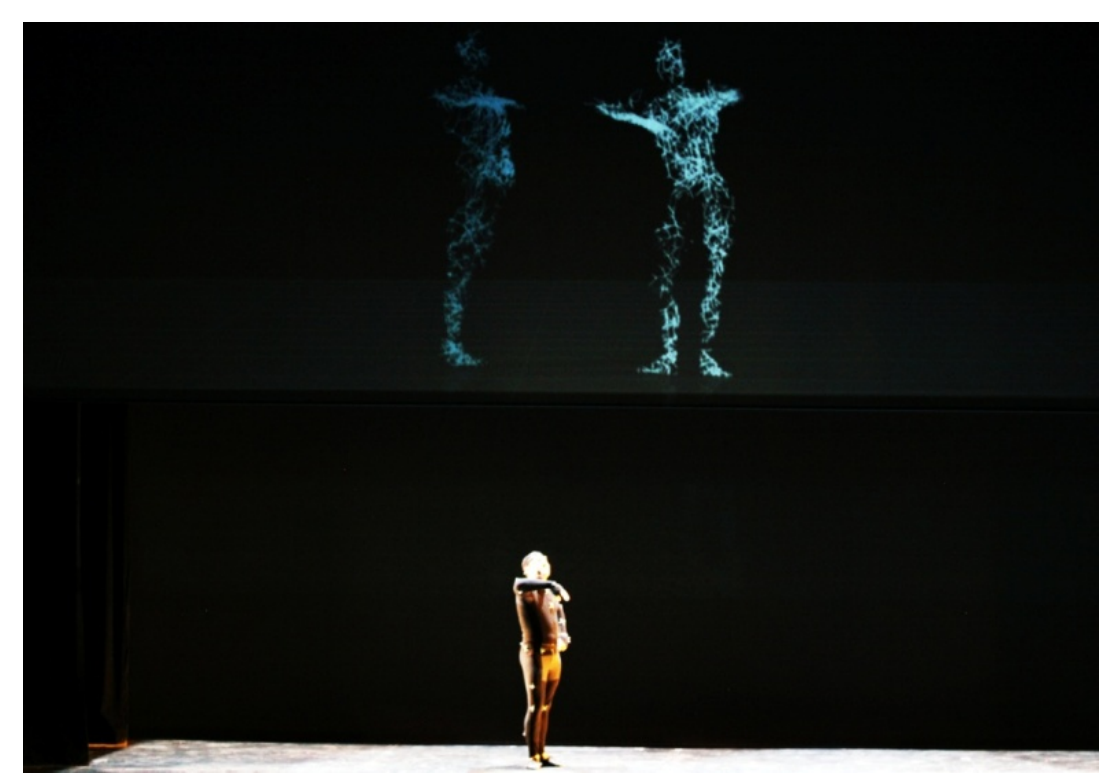

Scene from There is No Silence: Actor Patrick Wiabel performing an adagio that, while performed live, functioned as a duet when viewed in the same virtual scene with simultaneous playback of Marceau's original performance. 
VIS

Revista do Programa de Pós-graduação em Arte da UnB

\section{Evolving the Mediated Devising Environment}

Brought together in the projected 3D virtual scenes with layered video elements, the virtual avatars and live silhouettes along with the actors' physical presence onstage created a multi-faceted and engaging mediated devising environment. The arrival to its ultimate configuration spanned over four workshops and took several months and workshops to evolve.

Since the aim of the play was not only to present the story of Marceau the mime artist but also paint the portrait of his many professional and personal facets, There Is No Silence presented historical highlights from Marceau's life as well as included solos created and performed by each actor reflecting their personal view of the mime artform. With just a handful of physical set elements the mostly empty stage was often accompanied by projections of video and animated material creating a cinematographic treatment. This effect was furthered by the two horizontally and one vertically moving automated curtains made by the scenic designer Brad Steinmetz that effectively functioned as a camera iris, dynamically editing and framing both live actors and projections.

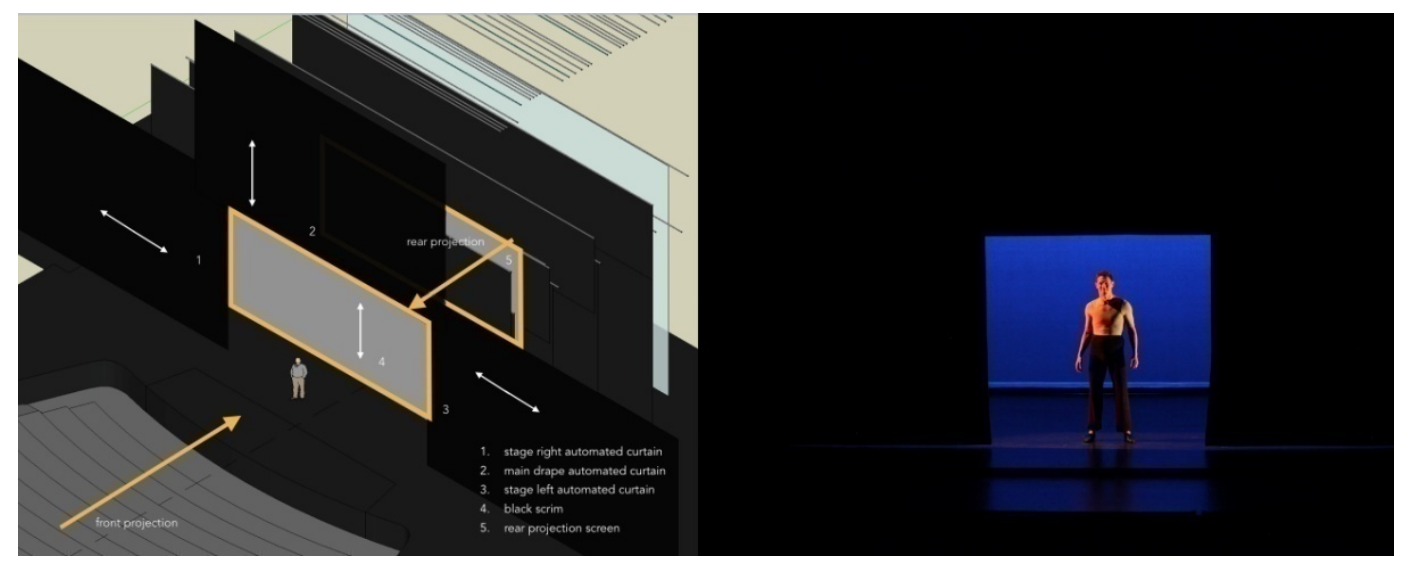

Caption: The three automated curtains moved vertically and horizontally allowing dynamic framing of action on the stage.

The motion capture system was set upstage of the automated curtains, allowing the concealing or revealing of the presence of the technology. The format of a live duet with Marceau's archived motion capture performance allowed Patrick Wiabel to choreograph the interaction between an actor, his live virtual avatar 
and a recorded avator of Marceau's. As Patrick evolved this duet from copying the adagio to creating a gestural dialogue with it, his virtual avatar connected him to the choreography and history of Marceau's movement ${ }^{9}$. Thevignette quality of this scene called for a neutral abstract treatment of the avatar designs that was unique to this moment in the play.

Many choreographers have engaged in working with motion capture and tracking technologies for live and recorded dance performances. Focusing on the relationship of physical and digital movement alone has yielded a gamut of fascinating work and philosophical discussions. While aiming at synergy with actors' movement, physical theatre often adds narrative layers such as plot, settings, characters and spoken word. Any one of these elements can have a profound impact on the outcome of engaging both physical movement and media in the devising process and thus require careful treatment.

Considerably influencing the devising of There is No Silence was the fact that Marceau was not only a performance artist, he was also a visual artist. His painting and printmaking practice, Marceau's first calling (Marceau, 2002), charted out the totality of his imaginary world: the vast mental images of cosmos and planets, nature and cities, his teachers and his audiences, all forming the surroundings of his character Bip. This work became a resource and inspiration for thevisual stylization of the projected virtual environments and also providedthe way an actor may interact with them. The visual world of Marceau could not just be a backdrop or part of a static scenic design, it needed to define the motion and feeling of the projected environments where virtual Bip ventured. The 3D projected environments developed by ACCAD students and staff were made in the style of Marceau's paintings. Some scenic elements in these virtual environments were pre-animated, some were driven by pre-recorded motion capture, a few puppeteered via motion tracking or triggered by a media operator in real time.

\footnotetext{
${ }^{9}$ Video of Patrick's duet with Marceau, https://vimeo.com/125201834
} 


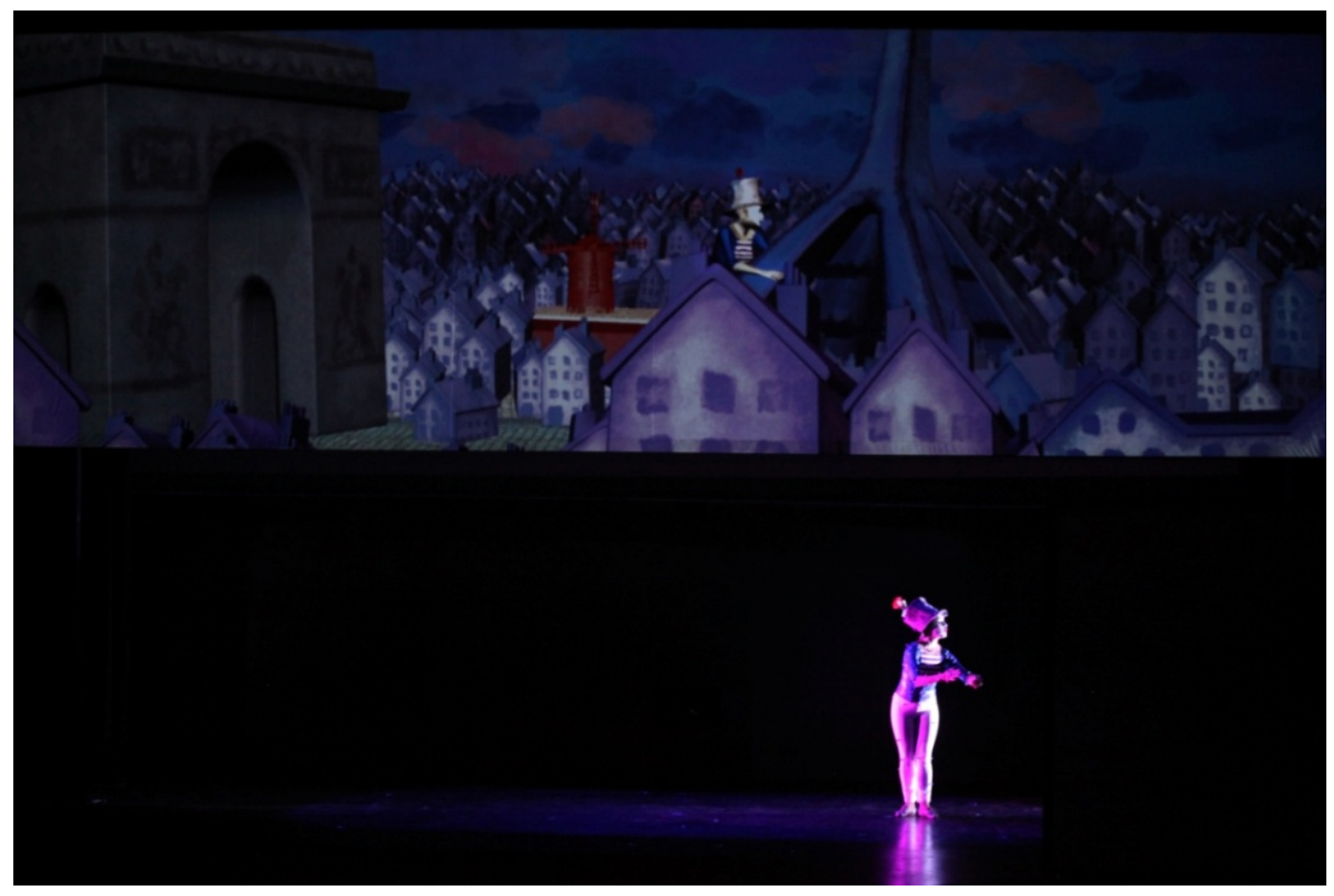

Caption: The 3D projected environments developed by ACCAD students and staff were made in the style of Marceau's paintings.

Performed by Sarah Ware, the character Bip engaged in non-mediated interactions with many physically appearing characters in the play, such as Marceau's lover/wife and children. Bip also connected with a virtual avatar, a digital puppet that, unlike the neutral and abstracted motion capture figures of Marceau and Patrick's duet, had a more immediate and stylistically continuous connection with both the physical and imaginary worlds of Marceau's. Another distinction was that Patrick wore a costume over his motion capture suit for all scenes in the play other than his duet with Marceau, whereas Sarah had optical sensors embedded in her costume of Bip allowing her to quickly step in and out of the mocap tracking state. While physically on an empty stage and sometimes supported by the un-markered members of the acting ensemble, Sarah's avatar stepped over buildings, hugged the Tour Eiffel, hopped around North America, did a cartwheel on the Golden Gate bridge and chased a fluttering heart among the $\operatorname{stars}^{10}$.

\footnotetext{
${ }^{10}$ Video excerpt from the play, https://vimeo.com/125201835
} 


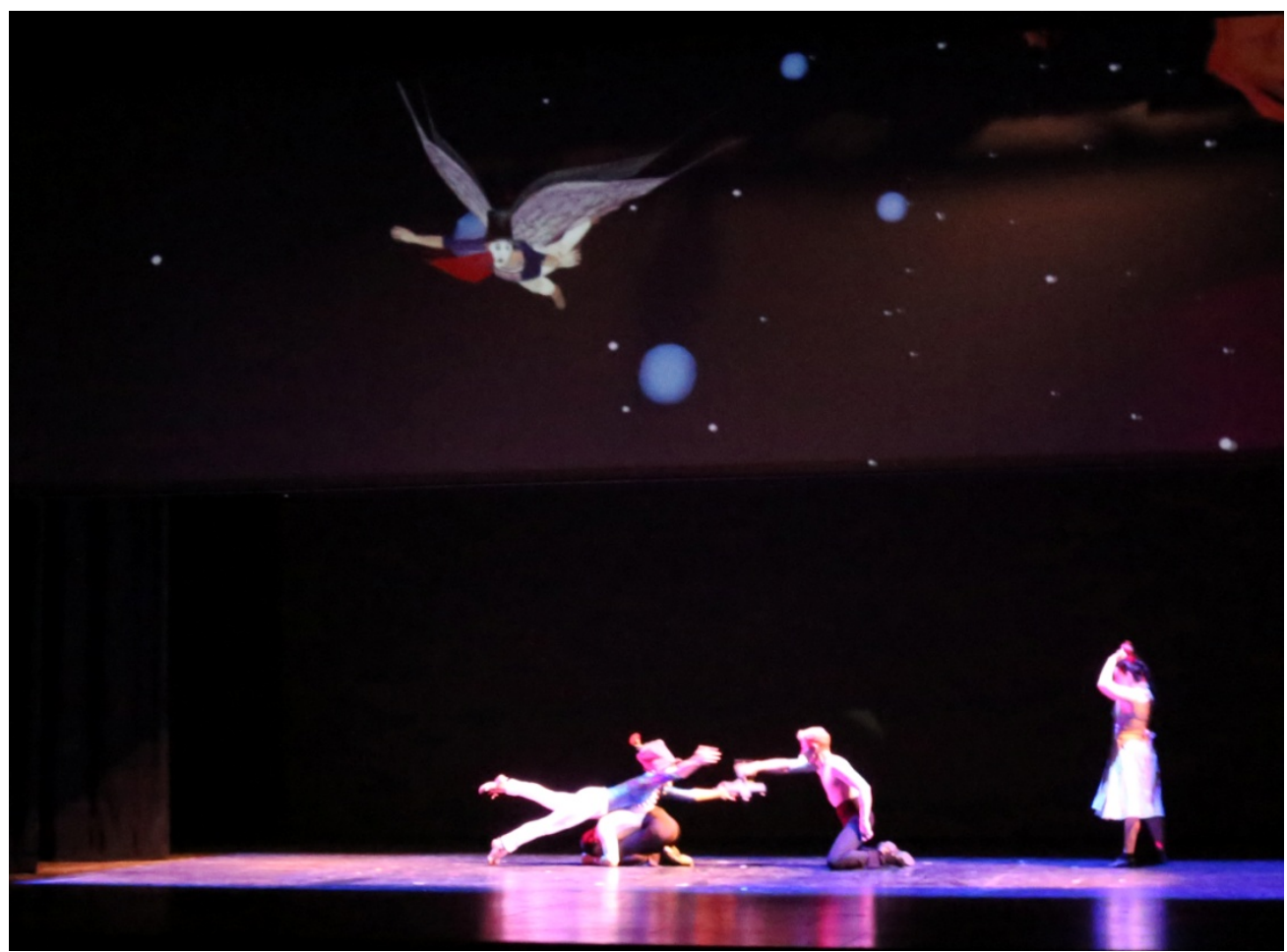

Caption: Scene from There is No Silence, Sarah Ware is assisted by members of the ensemble in creating the illusion of a virtual Bip flying after fluttering heart animated via a mocapmarkered prop

Sometimes a live actor also performed behind a projection surface and was visible in a silhouetted form. First developed in one of our pre-production workshops ${ }^{11}$ the methodology for devising scenes with projections was carried over intothe making of the play.It relied on the ability of actors to improvise and react to the animated projections, controlling the integration of their silhouettes or mocap driven avatars into the virtual worlds. One of the inspirations for this setup stemmed from the performance work of Miwa Matreyek ${ }^{12}$.

The final media projection setup with live mocap performance for the play consisted of a single large rear projection screen: looking at the view of their avatar via rear projected feedback in front of them, the actors weresimultaneously facing the audience. Occasionally Sarah's virtual avatar would appear in a portable projection screen brought onto the stage for selected scenes and placed stage

\footnotetext{
${ }^{11}$ Video documentation of development workshop, https://vimeo.com/128533113

12 Video portfolio of Miwa Matreyek, https://vimeo.com/matreyek
} 
VIS

Revista do Programa de Pós-graduação em Arte da UnB

left. This screen was also used for creating silhouetted appearance of another actor upstage thusallowing the silhouette and the virtual avatar to interact in a combined projection.

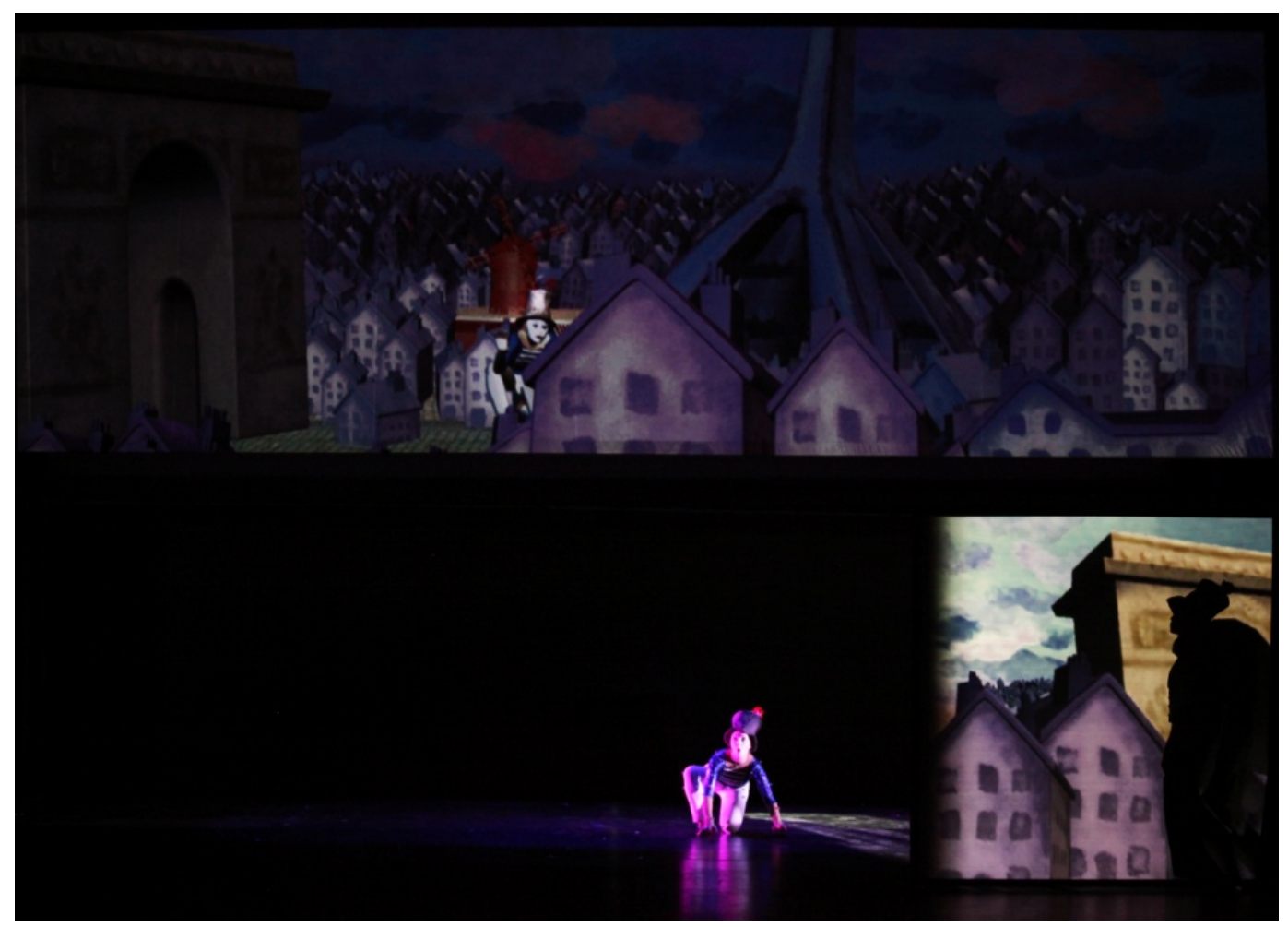

Caption: In the devising and production setup, looking at the view of their avatar and silhouette via rear projections downstage of them, the actors weresimultaneously facing the audience.

As we also experimented with facial motion capture during our workshopping process, a face puppet ended up being included in one of the mediated scenes of the play. This mise-en-scène element was based on a sun character commonly found in Marceau's paintings that watched Bip and reacted to his presence. Although the ultimate solution for animating the sun faces was facial performance capture, in earlier workshops we experimented with puppeteering the sun face via simple physical props with attached optical markers. Their rotation and translation controlled shifts between four basic facial expressions, gaze and eye blinking ${ }^{13}$.

\footnotetext{
${ }^{13}$ Video documentation of face puppets, https://vimeo.com/125205092
} 


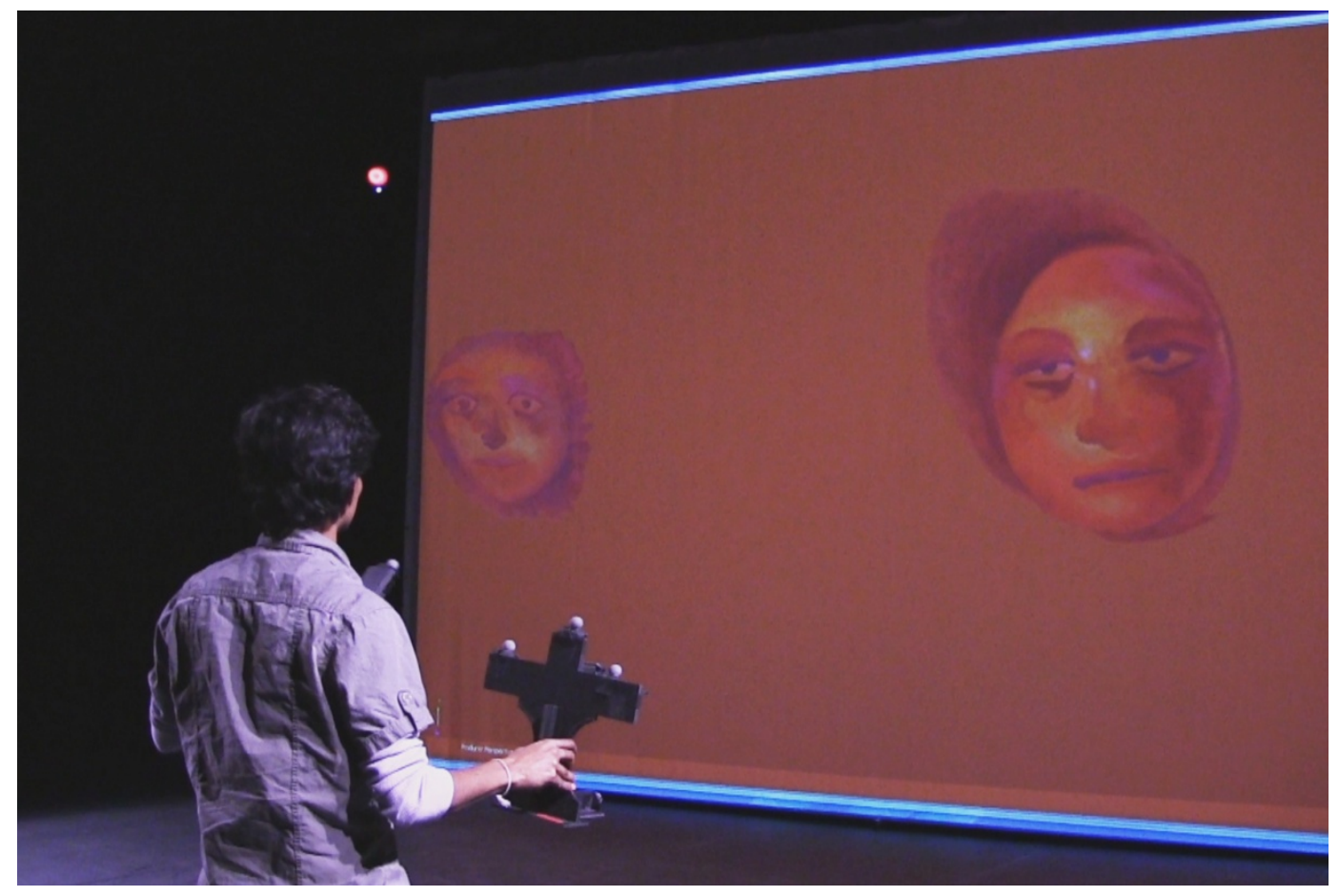

Caption: Sun face puppeteered with mocap props.

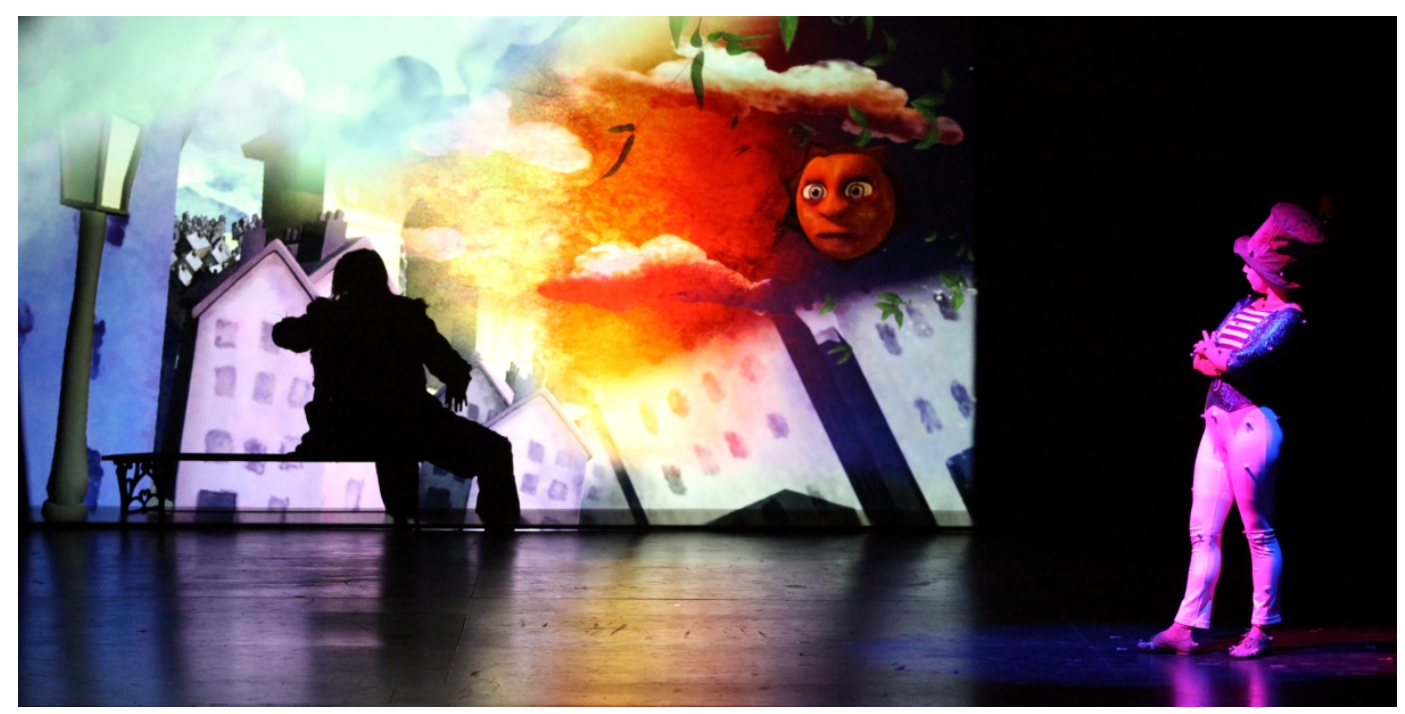

Caption: A recording of a Sun face puppeteered with facial motion capture triggered by the media operator in dialogue with a silhouetted live performer.

\section{Discussion}

The research of methodology for devising with live mocap and other media was a particularly exciting and challenging part of the journey. By engaging the audience in the dialogue at several work-in-progress showings, we were able to establish the audience's interest in watching a live actor along with his/her ava26 
tar performing side by side. This became a choice rather than locating a live actor off-stage. It allowed the viewer to juxtapose the live and virtual performance, examining its nature and agency, contrasting the bareness of stage with the richness of the virtual worlds.

Working with non-autonomous virtual avatars and simultaneously visible live performers often made us ponder the nature of this dual presence and reminded of the fascinating effect of a puppet. Although virtual avatars are technically full body puppets, unlike physical puppets, they do not obscure the presence of the puppeteer. The puppeteer in turn also does not have a haptic feedback of a physical puppet that they manipulate or wear. This can be a blessing and a challenge. While the choice to expose or purposefully hide the puppeteer is clear, the lack of thepuppet's physicality demands great proprioceptive imagination and skills from the performer. Otherwise the natural tendency of an actor is to perform as "self", which works better in situations when a virtual avatar is proportioned similarly to the performer, this does not work well in avatars with drastically different proportions or non-human designs. When writing about the rules of effective puppetry, Colette Searls (2014: 298) discusses the principle of unity that calls "to make fictional characters convincingly unified within themselves and their environment" appearing to "physically react, consistently and reliably, as a living being would.". While we expected the avatar to fit seamlessly with the virtual worlds, we continue to be intrigued by the presence of the puppeteer that is isolated from the puppet and can be perceived as performing onits own right.

Yet another type of live avatar devising was done in the context of interacting with Marceau's archival performance data. The real-time duet devised and performed by Patrick Wiabel live and through his virtual avatar was one of the most successful live mocap scenes in the play. It was enthusiastically received by the audience at every performance. "Inserting" himself in the space of Marceau's virtual presence, reacting to his gestures and timing in a way that suggested a believable real time interaction while physically remaining on an empty stage, offered a different twist on Marceau's proclaimed goal of mime being the art of "making the invisible visible". 
Topher (Christopher) Maraffi explores a similar idea of such dialogue between the real and the pre-recorded virtual performer in the context of his Performatology research, manifesting in the delightful experiments such as Theatre of Avatar: The Magic Mirror Game. He describes this piece as "visualizing the effect of making an autonomous agent mimic and improvise with an embodied actor through dramatic gesture" 14 and succeeds in creating a compelling merger of the virtual and physical acting space.

We find an echo of this sentiment in how Dawn Tracey Brandes describes the characters in Handspring Company's play Or You Could Kiss Me. Throughout the play the two main characters, A and B, are brought to life both by actors and by puppets that the actors puppeteer. She writes "By representing A and B in triplicate, Or You Could Kiss Me unsettles the notion of character as a unified entity that exists in a clear one-to-one relationship with the actor portraying it", and continues, "Thus, the postmodern character, if such a thing can be conceived, is one of a division and construction, surface and masks." (Brande, 2014: 246).

Another way of looking at the scenario of a character embedded in a virtual reality co-present with live action, is that the link between Patrick and Sarah's bodies and their avatars became an interface for interacting with the archival performance data and the painterly environments, transforming the physical set into an augmentedone,synergistically adding the projected virtual set and characters. The live actors activate the virtual space through their avatars. Sometimes they appear as shadows of live performers and at other times dominate the stage through their dynamic impact on the projected virtual world, especially in the quickly transforming flying sequences.

In order to take full advantage of this paradigm in script writing,the actors' relationship with the mediated environment has to be given an opportunity to evolve. The natural path of such evolution in our process was through improvisation. The actors improvised their movement as virtual avatars, silhouettes and

${ }^{14}$ http://www.chrismaraffi.com/ 
even puppeteers during the devising workshop. The evolving script of the play continued to leave room for this process all the way to the end.

Authoring through improvisation is the approach described by Basil Jones in developing the roles of puppets at the Handspring Company. "During these periods the script- writer effectively played the role of onlooker. Generally what he did was to observe the various sequences, and those that were approved by the director were... included into the working script and used to rehearse the play." (Jones, 2014: 64). This description works rather well too for our process of evolving the script through the mediated devising environment.

Marc Coniglio (2015: 279) alludes to a mediated performance environment as an instrument and proposes that the most synergy is achieved when performers "must adapt [to it] with extreme rigor". While the instrument analogy is a great metaphor for media, in dance performance where the focus is primarily on choreographing physical and digital movement, a puppet may be an alternative metaphor for media in theatre. In both case learning and practicing the totality of technologies in the devising space is critical.

This burden however does not fall on the actors' shoulders alone. The development of a complex technological devising environment also needs to consider the role of technology or media operator, who is not only responsible for following the cues but provides additional content manipulation by moving the virtual camera, modulating the intensity of a real-time effect, providing elements of real-time animation via a mouse, a keyboard or haptic devices in ways that are more challenging than button pushing. Effectively a puppeteer of the mediated environment, a computer animator or interactivity designer naturally fits this role and such experience offers exciting potentials for developing live performance, virtual production and interactive environments alike.

During the journey of devising There Is No Silence the partnership between actors and media designers/operators started with puppeteering a simpler environment where actors movements' made clouds roll and shapeshift across the projected sky while also effecting physical lighting in the space. Along with the 
VIS

Revista do Programa de Pós-graduação em Arte da UnB

actors' movements affecting the projection, the operator provided additional realtime manipulation of lighting and cloud quality, making this an exercise in collaborative puppeteering. This system evolved into working with elaborate $3 \mathrm{D}$ virtual environments based on Marceau's paintings with multiple interaction points and props with sensors.

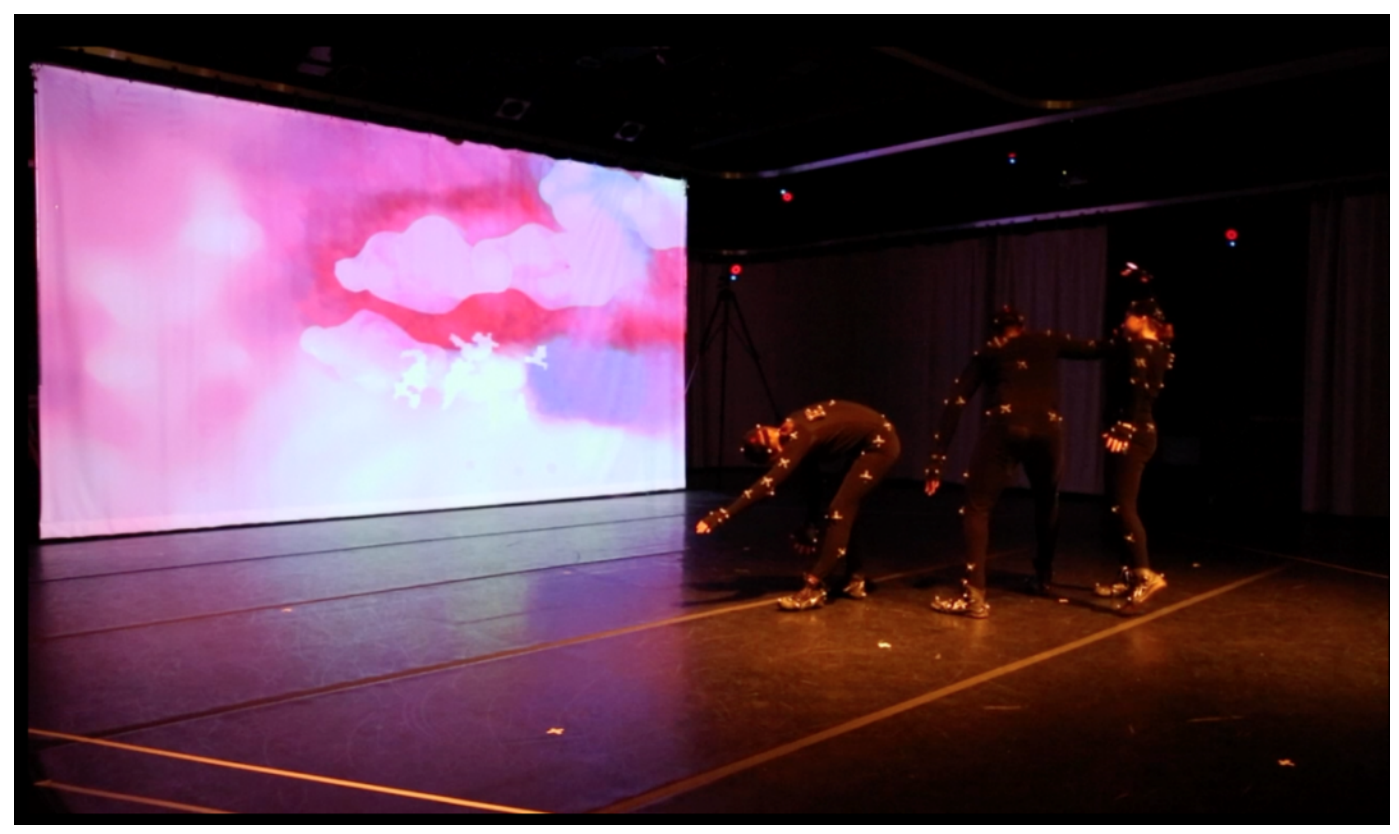

Caption: In an early experimentation the actors animated cloud rolling and shape-shifting with their motion tracked performance"

While puppeteering or performing as an avatar, the quality of visual feedback to the actors cannot be overestimated. In the final version of the setup it was facilitated via screen projections and physical tape spikes on the stage floor that indicated locations of some of the virtual environment elements in relationship to the avatar, i.e. Golden Gate Bridge for which Sarah and her avatar needed to be in the correct location. A combination of screen feedback, floor spikes and rehearsals made it possible to achieve the desired effect but a better three dimensional and haptic feedback in the mediated devising environments remains one of the most pressing challenges for making the interaction more nuanced and devising opportunities more sophisticated.

Daniel Kade, OğuzhanÖzcan and Rikard Lindell (2013: 233) also identify this issue in the context of motion capture production environments suggesting 
that the solution to this challenge should be primarily achieved through the development of immersive technologies. While this certainly is a very worthy goal, especially from the standpoint of also evolving the audience experience, for actors devising with technology a physical theatre training approach can also be extremely helpful. After all, in mime training one learns relating to an invisible environment through the development of proprioceptive skills. The imagined environment is unavailable to the actor's in their immediate kinesphere and is mapped entirely through performer's movement. This relationship is similar to the situation of a projected virtual environment due to its two dimensional presentation. The proprioceptive skills come into play for an actor looking at a projection to ensure that their virtual avatar's movements match the three dimensional virtual landscape. A very exciting extension of the idea of training to perform with a virtual avatar can be found in research of Ali Mazalek's group such as recognition of self in virtual avatars (Mazalek, 2013: 83) and puppet controlled virtual avatars (Mazalek, 2010: 66-73). Their research suggestedthat learning to perform or puppeteer a virtual biped through motion capture can improve a person'sability to control virtual props and environments through simpler interfaces. This points to a path towards a more nuanced integration of actors in mediated and digital puppetry works. We begin to develop these ideas in our current experimentations with performance in immersive room scale virtual reality scenarios and digital puppets.

For those who took part in it, the journey of making There is No Silence, while honoring the heritage of the great Marcel Marceau, opened up exciting paths for evolving the humanist message of his work in the era of rapid technological and cultural shifts. Devising with media and technology is a critical experience for acting, scriptwriting, set design and lighting design students in the field of theatre as well as animators and media artists. Continuing to uphold human performance and presence in the heavily mediated scenarios is important for not losing sight of the human condition against the backdrop of the technologically facilitated visual abundance. 


\section{References}

BRANDES, Dawn Tracey. A Total Spectacle but a Divided One in POSNER, N. Dassia; ORENSTEIN, Claudia; BELL, John (org.). The Routledge Companion to Puppetry and Material Performance. New York: Routledge, 2014.

COGNIGLIO, Mark. Conclusions: Reflections, Interventions, and the Dramaturgy of Interactivity. Digital Movement: Essays in Motion Technology and Performance. Edited by Nicolas Salazar Sutil and SitaPopat, 2015.

JONES, Basil. Puppetry, Authorship and the Un-Narrative in POSNER, N. Dassia; ORENSTEIN, Claudia; BELL, John (org.). The Routledge Companion to Puppetry and Material Performance. New York: Routledge, 2014.

KADE, Daniel, et all. An Immersive Motion Capture Environment.World Academy of Science, Engineering and Technology 73, 2013.pp. 233-239.

MARCEAU, Marcel. How I worked in the French Resistance and Created Bip as a Figure of Hope. Michigan Quarterly Review, Volume XLI, Issue 1, Winter 2002.

MAZALEK, Ali et all. Recognizing your self in virtual avatars. International Journal of Arts and Technology, Vol. 6, № 1, 2013.

MAZALEK, Ali et all. Recognizing Self. Puppet Controlled Virtual Avatars Proceedings of the 3rd international Conference on Fun and Games (Leuven, Belgium, September 15-17, 2010). Fun and Games '10. ACM, New York, NY. pp. 66-73.

SEARLS, Colette. Unholy Alliances and Harmonious Hybrids in POSNER, N. Dassia; ORENSTEIN, Claudia; BELL, John (org.). The Routledge Companion to Puppetry and Material Performance. New York: Routledge, 2014.

VINCS, Kim. Capturing dance and choroetopography: analyzing and visualizing complexity, ISEA 2011. 